\title{
Update on Hepatitis C Epidemiology: Unaware and Untreated Infected Population Could Be the Key to Elimination
}

\author{
Cristina Stasi $^{1,2}$ (D) $\cdot$ Caterina Silvestri $^{1} \cdot$ Fabio Voller $^{1}$
}

Accepted: 11 October 2020/Published online: 18 October 2020

(C) Springer Nature Switzerland AG 2020

\begin{abstract}
Globally, the World Health Organization (WHO) estimates that 71 million people have chronic hepatitis C virus (HCV) infection. A significant number of these will develop cirrhosis or liver cancer. Currently, during the COVID-19 outbreak, a high mortality rate has been found in patients with COVID-19 and cirrhosis. New direct-acting antiviral agents can cure more than 90\% of HCV-infected patients. The new WHO strategy has introduced global goals against viral hepatitis, including a $30 \%$ reduction in new HCV cases and a $10 \%$ reduction in mortality by 2020 . HCV transmission has changed considerably, reflecting both the evolution of medicine and health and social changes. The HCV is usually spread through blood-to-blood contact. After the discovery of HCV in 1989, antibody screening has drastically decreased the incidence of post-transfusion hepatitis. Nowadays, routine blood donor screening by nucleic acid amplification testing for the presence of HCV RNA has been introduced in many countries. It is conceivable that HCV screening could be offered to people born between 1946 and 1964 in the developed world and to people at high risk for $\mathrm{HCV}$ infection such as those who have received blood transfusions, blood products or organ donations before the 1990s, prisoners, health care workers, drug users and infants born to HCV-infected women. To achieve $\mathrm{HCV}$ elimination, health programmes should include improvement to access to health care services, increased screening and new projects to identify a submerged portion of patients with HCV infection. Submerged people with HCV infection are both people who are unaware of their condition and people diagnosed with HCV but not yet treated. Based on these premises, this review will examine and discuss the epidemiological changes in contracting $\mathrm{HCV}$, highlighting the ways in which to identify a submerged portion of patients with $\mathrm{HCV}$ infection.
\end{abstract}

Keywords Hepatitis C virus · Epidemiology · Screening · Public health · COVID-19

\section{Abbreviations}

CDC Centers for Disease Control and Prevention

COVID-19 Coronavirus disease 2019

DAAs Direct-acting antiviral agents

HBV Hepatitis B virus

HCC Hepatocellular carcinoma

$\mathrm{HCV} \quad$ Hepatitis $\mathrm{C}$ virus

Caterina Silvestri and Fabio Voller shared senior authorship

This article is part of the Topical Collection on Medicine

Cristina Stasi

cristina.stasi@gmail.com

1 Observatory of Epidemiology, Regional Health Agency of Tuscany, 50141 Florence, Italy

2 Department of Experimental and Clinical Medicine, University of Florence, 50134 Florence, Italy
HIV Human immunodeficiency virus

MSM Men who have sex with men

PWID People who inject drugs

WHO World Health Organization

\section{The State of the Art}

Acute hepatitis $\mathrm{C}$ virus (HCV) infection becomes chronic in most cases (55-85\%) [1]. Chronic infection can either lead to mild illness or develop into liver cirrhosis, liver failure and hepatocellular carcinoma (HCC). According to the Centers for Disease Control and Prevention (CDC), out of 100 people infected with HCV, around 60-70 will develop chronic liver disease, 5 to 20 will develop cirrhosis in a period ranging from 20 to 30 years and 1 to 5 people will die from the consequences of cirrhosis or HCC [2]. 
Chronic HCV infection without cirrhosis is however associated with worse quality of life and symptoms (e.g. mood disorders and fatigue) than those who do not have this infection [3]. On large cohorts of patients, it is also widely demonstrated that chronic HCV infection is accompanied by extrahepatic manifestations including lymphoproliferative disorders (e.g. cryoglobulinaemic syndrome and non-Hodgkin's lymphoma), type II diabetes mellitus, insulin resistance, cardiovascular disease and kidney disease [4].

In 2015, about 71 million people lived with HCV infection; in $2017,19 \%$ (13.1 million) of them knew their infection status and only $15 \%$ ( 2 million) of people already diagnosed with $\mathrm{HCV}$ infection received curative treatment in the same year. Overall, between 2014 and 2017, 5 million people received HCV infection eradication treatment, but in the same year, 1.75 million people had recently developed a chronic $\mathrm{HCV}$ infection [5].

According to $\mathrm{CDC}$ data, the number of deaths due to $\mathrm{HCV}$ infection in 2012 compared to that in 2015 increased from 18,650 to 19,629 (from 4.9 to 5.0 deaths/100,000) and decreased to 18,153 in 2016 (4.5 deaths/100,000) [6]. According to Eurostat data, Italy ranks in first place for the highest mortality rate due to viral hepatitis among the EU Member States, with 40 deaths from viral hepatitis per million inhabitants [7]. In an Italian study [8], conducted by analysing data from the National Registry of Causes of Death, on all deaths of individuals aged $\geq 20$ years, HCV infection was found in $1.6 \%$ (corresponding to 27,730 deaths). The mortality rate associated with $\mathrm{HCV}$ infection increases exponentially with age in both sexes and it is higher in southern Italy, with the highest peak among elderly people aged 60 or older.

According to World Health Organization (WHO) data, worldwide less than $5 \%$ of people with the chronic viral infection are aware of their condition. Effective diagnostic approaches are required in order to increase early detection of $\mathrm{HCV}$, as well as a link to care and treatment services [9]. At present, only 9 countries are on track to achieve the WHO HCV elimination targets by 2030 [10]. Moreover, the preliminary results from an international registry showed high mortality rates in patients with coronavirus disease (COVID-19) and cirrhosis, because COVID-19 can lead to deterioration in liver function. The overall mortality rate was $40 \%$. Patients with decompensated cirrhosis showed the highest death rate (between 43 and 63\%), compared to $12 \%$ for patients with liver disease without cirrhosis [11]. The Italian Association for the Study of the Liver and the Italian Society of Infectious and Tropical Diseases, in concert with the Association of Patients, grouped in an association called Alliance Against Hepatitis, now propose to immediately start joint HCV/COVID-19 screening [12].

According to the European Association for the Study of the Liver [13], given the new therapeutic options that allow for eradication of the infection, the focus of this branch of hepatology has moved onto screening, diagnostic strategies and access to treatment for infected people.

New direct-acting antiviral agents (DAAs) have drastically changed HCV management and hence, the reservoir of infection has taken a great interest in terms of HCV elimination. Submerged people with HCV infection are both people who are unaware of their condition and people diagnosed with HCV but not yet treated (Fig. 1).

The goal of public health programmes is to detect as many infected people as possible before they progress to clinical manifestations of the disease. This goal is possible, taking into account all routes of transmission.

Therefore, due to the importance of this matter, this review will examine and discuss the epidemiological changes in contracting $\mathrm{HCV}$, highlighting the ways in which to identify a submerged portion of patients with HCV infection.

\section{Epidemiology of Chronic Hepatitis C Virus Infection}

Gower et al. [15] showed that the global serological prevalence of people with a history of HCV - the presence of antiHCV antibodies-was $1.6 \%$ (range $1.3-2.1 \%$ ), a value that reached $2.0 \%$ among adults (defined as those older than 15 years old). The test for anti-HCV antibodies may remain positive even after virus clearance; moreover, a minimum rate may be falsely positive.

Therefore, the estimated prevalence of people in whom HCV RNA is detectable is $1.1 \%$ (range $0.9-1.4 \%$ ) in the entire population and is $1.4 \%$ when we only consider those over 15 years of age.

Saraswat et al. [16], taking into account 15 countries (Argentina, Finland, Greece, India, Ireland, Israel, Luxembourg, Mexico, Mongolia, Netherlands, New Zealand, Norway, Poland, Russia, South Africa), showed a prevalence of HCV RNA that varied between $0.13 \%$ in the Netherlands and $2.91 \%$ in Russia.

A recent review [17] published the viraemic prevalence in 17 countries (Bahrain, Bulgaria, Cameroon, Colombia, Croatia, Dominican Republic, Ethiopia, Ghana, Hong Kong, Jordan, Kazakhstan, Malaysia, Morocco, Nigeria, Oman, Qatar, Taiwan). In this study, the viraemic prevalence varied between $0.2 \%$ in Hong Kong and $2.4 \%$ in Taiwan, while the largest viraemic populations were in Nigeria $(2,597,000$ cases) and Taiwan (569,000 cases).

Moreover, of the estimated 10.2 million people incarcerated worldwide in 2014, Dolan et al. [18] estimated that $15.1 \%$ have $\mathrm{HCV}$ infection.

The HCV is a major cause of liver disease. The incidence of hepatocellular carcinoma increases in both sexes with increasing age. In HCV patients, the cumulative risk of evolving to hepatocellular carcinoma in the age group between 40 and 
Fig. 1 Most important world and Italian data on HCV. The data were obtained from a variety of sources, including estimated data by ${ }^{*, \alpha}$ WHO $[1,9],{ }^{\phi}$ Polaris Observatory [10], **Alleanza contro l'Epatite (Alliance Against Hepatitis) [14]
World data

71 million *
people
HCV chronically
infected

\author{
$80 \%$ of high- \\ income countries $\phi$ \\ are not on track to \\ meet HCV \\ elimination
}

2019
$160,000-170,000$
people diagnosed
with HCV but not yet treated
70,000-130,000
people who are
unaware of their
condition

$80 \% \alpha$ of eligible persons with $\mathrm{HCV}$ infection treated

Italian data

74 years is $21.6 \%$ among males and $8.7 \%$ among females [19]. The main routes of HCV transmission were summarised by the WHO [1].

In April 2014, the WHO published the first guidelines on $\mathrm{HCV}$, which note how HCV infection takes a different path than other chronic viral infections (including human immunodeficiency virus (HIV) infection) because the treatments currently available allow eradication. The guidelines are divided into nine recommendations, which include various aspects: the indication to increase the number of people subject to screening, suggestions on how to reduce damage to the liver and which treatments to use for different cases, according to the drugs approved up to December 2013 [20]. These guidelines were then updated in 2016 and 2018 because other new drugs had been approved in the meantime [21]. The WHO's follow-up resolution called on the Member States to develop and put into practice a national programme based on epidemiological data. The new WHO strategy [22] introduces global goals against viral hepatitis. This includes a $30 \%$ reduction in new cases of hepatitis B virus (HBV) and HCV infections and a $10 \%$ reduction in mortality by 2020 .

\section{People at Risk of Hepatitis C Virus Infection Transmission and Reservoir of Infection}

\section{HCV Transmission by Blood}

HCV transmission has considerably changed, reflecting both the evolution of medicine, in particular the cloning of the $\mathrm{HCV}$, and health and social changes. The main modes of
HCV transmission are parenteral exposure, unapparent parenteral transmission and occupational exposure. Blood transfusion was the main risk factor for $\mathrm{HCV}$ infection before donor screening for surrogate marker testing for non-A and non-B hepatitis which began in the mid-1980s, followed by screening for antibodies to HCV in 1990 [23]. After 1985, the incidence of post-transfusion HCV infection has been halved by excluding HIV-positive people in developed countries [24]. Moreover, since 1993, the availability of more sensitive tests has further reduced this prevalence. However, given that antiHCV antibodies are not detectable for several weeks or months in recently infected donors' blood, in some countries, all donations are tested by nucleic acid amplification tests for the presence of HCV RNA. The WHO reports that 39 countries do not routinely screen blood transfusions for blood-borne viruses [24, 25]. The generalised epidemic of HCV infection in Egypt is an example of health care-associated transmission originating from unsafe injection practices, where, in 2015, HCV RNA prevalence was $7.7 \%$ in some regions [25].

In Italy, in 2013, the prevalence was $80.8 / 100,000$ in first time donors and the incidence rate was $2.5 / 100,000$ in first time donors [26].

Blood-to-blood HCV transmission also occurs through haemodialysis and is more evident in developing populations. According to recent data, the range is between 8.5 and $62.7 \%$ [27]. However, the results of the dialysis outcomes and practice patterns study, conducted in 308 dialysis centres in the industrialised world (France, Germany, Italy, Spain, the UK, Japan, and the USA) for a total of 8615 patients on haemodialysis, showed a prevalence of anti-HCV positive patients that ranged between 3 and 23\% [28]. 
In Italy, from 1995 to 2003, the prevalence of HCV infection among long-term dialysis patients decreased significantly from 30.6 to $15.1 \%(P<0.001)$ [29].

\section{Baby Boomers}

Baby boomers are people born after the Second World War roughly between 1946 and 1964. HCV infection is common among baby boomers [30], probably because the age cohort of baby boomers comprises a large proportion of people who have used illicit drugs in their lifetimes.

Considering the ongoing transmission of $\mathrm{HCV}$ in people who inject drugs (PWID), it is important to highlight harm reduction efforts due to needle and syringe programmes and opioid substitution therapy. Moreover, DAA treatment in these populations at higher risk of contracting infection could potentially decrease transmission but decrease re-infections much more.

In a recent review, Joy et al. [31] divulge the early HCV epidemic dynamics in North America. In particular, they demonstrate that the expansion of genotype 1a before 1965 suggests that nosocomial or iatrogenic factors rather than past sporadic behavioural risk (such as experimentation with injection drug use, unsafe tattooing, high-risk sex) were key contributors to the HCV epidemic in North America. These results, therefore, suggest to increase rates of HCV screening and treatment and reduce stigmatisation around HCV screening and diagnosis.

Starting from 2012, the CDC recommended 1-time HCV testing of all baby boomers [32].

\section{Intravenous Drug Users}

$\mathrm{HCV}$ infection is very common in people who inject drugs, in whom HIV co-infection is very common. Injection drug use is the main risk factor for HCV transmission in both Europe and the USA. A recent systematic review has been conducted to estimate the prevalence of anti-HCV among PWID, identifying 77 eligible countries out of 152 countries considered, corresponding to about $82 \%$ of the estimated world population of PWID [33]. The results of this review showed that the prevalence of $\mathrm{HCV}$ infection in drug users exceeded $80 \%$ in 12 countries including Italy, was between 60 and $80 \%$ in 25 countries including the USA and Asia, was between 40 and $80 \%$ in 24 countries including Australia and Britain and was less than $40 \%$ in 16 countries, including Turkey. The data were not available for 74 countries. The number of new cases of HCV declined precipitously between 1990 and 2005.

Currently, PWID represent the majority of people with $\mathrm{HCV}$ in many countries throughout the world. New cases of HCV have increased threefold between 2005 and 2015. Approximately $50 \%$ of PWID have been exposed to HCV, and $25 \%$ of these people are under the age of 25 . However,
PWID access health care and receive HCV treatment at much lower rates than baby boomers. There are many reasons for this, such as no other medical disorders associated with $\mathrm{HCV}$ that require medical care, and a higher rate of mental health issues, which is why physicians consider PWID to be noncompliant.

\section{Sexually Transmitted Disease}

This route of transmission is possible in $\mathrm{HCV}$ patients, but less frequent than in HBV patients (about 1\%). The incidence rate of HCV transmission of 0.37 per 1000 person-years was observed in monogamous couples during a follow-up period of 10 years [34]. HCV transmission is higher in heterosexuals with multiple partners, or in those in whom a sexually transmitted infection coexists $(0.4-1.8 \%$ per year) compared to transmission between monogamous heterosexuals [35-37]. Recently, HCV is considered an emerging sexually transmitted infection among men who have sex with men (MSM), particularly in HIV-infected patients. People with HIV are at high risk of $\mathrm{HCV}$ infection. HCV/HIV co-infection is common, the prevalence of which is between 9 and $37.3 \%$ and is probably due to the common route of transmission of these infections [38].

A UK survey of HIV has revealed an increase in new cases of HCV in MSM from 6.86 cases/1000 person-years in 2002 to 11.58 in 2006, almost double, with no apparent change in testing policy. Recently, there has been a change in current HCV infection, with an increased incidence in MSM than in PWID [39]. This trend was confirmed in the analysis of the Swiss study outlining an increase of 18 times the incidence of new cases in MSM from 0.23 (95\% CI: 0.08 to 0.54 ) per 100 person-years in 1998 to 4.09 (95\% CI: 2.57 to 6.18) in 2011 [40].

In European studies, the predominant genotype in MSM was the genotype 1a (59\%), with a surprisingly high percentage of the $4 \mathrm{~d}$ genotype (23\%) [41].

Worldwide, about $30 \%$ of HIV-infected people are HCV or $\mathrm{HBV}$ co-infected. Generally, HIV/HCV co-infection is more common in individuals who have a history of injection drug use. Several studies have also shown that these co-infections are at major risk of liver fibrosis progression with consequent evolution to cirrhosis. HIV-infected individuals are at risk of contracting viral hepatitis. In Tuscany, in 5 years of monitoring, it has been seen that co-infected patients showed a prevalence of $7.8 \%$, of whom $91.5 \%$ were Italian [42]. In HIV/ $\mathrm{HCV}$ co-infected people, $52.8 \%$ were injection drug users. HCV patients did not show a particular association with advanced HIV disease, possibly because the tests were performed earlier. The reasons associated with testing were mainly related to the perception of risk, or the test was carried out because it was offered by Drug Addiction Services or offered in prison. Therefore, these data do not represent a random sample of the whole sub-population. These data show a higher 
prevalence of $\mathrm{HCV}$ infection in HIV-positive foreigners than in Italians. Moreover, HIV/HBV co-infected patients were at higher risk of being a late presenter, having advanced HIV disease and AIDS. The prevalence of HIV/HCV is high in injection drug users and the age group 35-59 years. This also confirms the finding of a less-advanced stage of the disease in these patients, reasonably due to a greater perception of risk of disease that could lead to earlier testing [42].

\section{Interfamilial Transmission}

According to a recent meta-analysis, the risk of vertical transmission was $5.8 \%$ (95\% CI, 4.2-7.8\%) in children of mothers with anti-HCV antibodies and HCV RNA positive. Prevalence was up to $10.8 \%$ (95\% CI, 7.6-15.2\%) for children of HIV-positive women.

Contrary to what was observed for HIV transmission, in the case of $\mathrm{HCV}$, the execution of caesarean section did not prove useful in reducing the risk of neonatal infection, although prolonged rupture of the membrane can increase risk. There is no evidence of infection transmission through breast-feeding, which is therefore not contraindicated [43].

As outlined by Indolfi et al. [44], the limits of several studies on horizontal transmission are due to limited phylogenetic analyses, demonstrating that different individuals of the same family or household are infected with viruses with very similar genomic sequences. The virological confirmation that a horizontal transmission event has occurred is supported by a high rate of sequence homology found between the HCV genome of infected patients and the HCV genome of their infected contacts. Moreover, interfamilial HCV transmission is called into question for both non-sexual transmission mediated by close contact with infected domestic objects and sexual transmission. It is for this reason that the prevalence reported in several studies is extremely variable [44].

\section{Health Care Worker Transmission}

Unapparent blood contact causes HCV transmission. Therefore, in addition to patients, health care workers may be at risk of contracting HCV infection in the event of accidental exposure to the blood of infected individuals. Studies reveal, if one ignores the limitations of the data, an average risk after parenteral exposure of $1.9 \%$ [45].

\section{Screening: Is this the Correct Way?}

On the occasion of World Hepatitis Day in July 2019, the WHO called on all states to 'invest in eliminating hepatitis'. A total of 124 countries out of 194 have developed plans to reach this goal, but over $40 \%$ of national plans do not have dedicated budget lines to support the actions aimed at achieving elimination [46]. Furthermore, globally, less than 5\% of people with chronic viral infection know their status (unknown infection) [24]. Against this background, screening for HCV infection can be considered a useful pathway for revealing unknown infected people. In 2013, the CDC [47] considered screening for adults born between 1945 and 1965 (baby boomers). These individuals must be tested at least once for HCV infection (without prior assessment of HCV risk factors). The anti$\mathrm{HCV}$ test was also recommended for drug users, for those who have always used drugs by injection or for those who have used drugs a few times in previous years, people who received concentrations of coagulation factors produced before 1987, those subjected to long-term haemodialysis or those with persistently abnormal levels of ALT or HIV infection. Screening for HCV is also recommended for individuals who have received previous transfusions or organ transplants, including people who have been informed that they received blood from a donor who later tested positive for HCV infection or who had received a blood transfusion, blood components or organ transplant before July 1992. The CDC recommended performing the $\mathrm{HCV}$ test following skin or mucous membrane exposure to needles or sharp objects contaminated with HCV-positive blood. Moreover, for people who may have been exposed to $\mathrm{HCV}$ within the last 6 months, the execution of the HCV RNA test or follow-up for HCV antibody is recommended. In 2017, the American Association for the Study of Liver Diseases and the Infectious Diseases Society of America [48] instead recommended performing the HCV test for people born between 1945 and 1965 (ascertained by the country of birth) without a risk assessment. It was recommended that all other people be screened for HCV infection risk factors and that a one-off test be performed for all people with associated changes, conditions and circumstances and risk of HCV infection. According to them, all people with active HCV infection must be referred to a service that can ensure complete management of the disease.

In Europe, Crespo et al. [49] recently carried out a population-based, cross-sectional study from July 2015 to April 2017 with the aim of determining the prevalence of HCV and assessing the cost-effectiveness of a screen-and-treat strategy in the Spanish population. A total of 12,246 participants aged 20-74 (58.4\% females) were enrolled in this study. The results showed that the prevalence of anti-HCV was $1.2 \%$, whereas the prevalence of detectable HCV RNA was $0.3 \%$, highlighting a misalignment between anti-HCV prevalence and viraemia and a greater awareness of HCV status than previously assumed. The highest prevalence of anti-HCV (1.6\%) and of HCV RNA positivity $(0.4 \%)$ were found in subjects aged $50-74$ years. $59.8 \%$ of the anti-HCV positive individuals were aware of their serological status. When considering a treatment cost of $€ 7000 /$ patient, implementing screening programmes is cost-effective across all age cohorts, particularly in those aged 50-54. 
Recently, recommendations for 'Screening for hepatitis C virus infection in adolescents and adults: a systematic update of the review' have been published by the US Preventive Services Task Force [50]. These suggest an extension of the proportion of the population to be screened for $\mathrm{HCV}$ infection to all adults aged 18 to 79 years (USA Task Force Preventive Services, 2019). The assessments are qualified with a type B level of proof or there is a high certainty that the net benefit is moderate or there is an unmistakable certainty that the net benefit is moderate to substantial.

Recently, the use of the rapid oral HCV antibody test, reflex nucleic acid testing and $\mathrm{HCV}$ core antigen tests has the potential to simplify the approach to HCV diagnosis. Having these tests available in different settings (point-of-care testing) for individuals at risk for $\mathrm{HCV}$ infection may be an appropriate strategy to increase the number of people who know their serological status and facilitate the link to care and treatment [51].

The outbreak of COVID-19 has drastically changed the diagnosis, treatment and follow-up of patients with chronic $\mathrm{HCV}$ at a time when general practitioners are actively engaged in the early detection of SARS-CoV-2 infection among their patients. Telemedicine has certainly continued to allow specialists to prescribe DAAs as well as monitor patients under treatment, whereas screening may still be implemented. As pointed out by the Alliance Against Hepatitis Association (Alleanza contro l'Epatite) [12], joint HCV/SARS-CoV-2 screening could accelerate the path towards the elimination of HCV and the achievement of the objectives indicated by the WHO for 2030.

\section{Conclusions}

This review provides evidence of changing epidemiology of $\mathrm{HCV}$ transmission with a higher prevalence in the older population. Therefore, given the high prevalence in these groups of patients, it is conceivable that anti-HCV screening, with subsequent detection of HCV RNA, could be offered to people born between 1946 and 1964 to greatly reduce HCV infection worldwide via antiviral treatment. Programmes to eliminate $\mathrm{HCV}$ should include improvement to access to health care services, increased screening and new projects to identify a submerged portion of patients with chronic $\mathrm{HCV}$ infection.

Yet it is truly necessary to remember the hundreds of thousands of people in the developing world who have very limited access to HCV diagnosis and treatment.

Moreover, due to the high mortality rates in patients with COVID-19 and cirrhosis, joint HCV/COVID-19 screening could be highly recommended.

Authors' Contributions Stasi C wrote and revised the manuscript; Silvestri C and Voller F critically revised the manuscript for important intellectual content and have given final approval of the version to be published.

\section{Compliance with Ethical Standards}

Competing Interests The authors declare that they have no competing interests.

\section{References}

1. World Health Organization. Hepatitis C. 2020. Available at: https:// www.who.int/news-room/fact-sheets/detail/hepatitis-c. Accessed 27 July 2020.

2. Centers for Disease Control and Prevention. Hepatitis C questions and answers for health professionals. 2020. Available at : https:// www.cdc.gov/hepatitis/hcv/hcvfaq.htm. Accessed 7 Aug 2020.

3. Dirks M, Haag K, Pflugrad H, Tryc AB, Schuppner R, Wedemeyer $\mathrm{H}$, et al. Neuropsychiatric symptoms in hepatitis $\mathrm{C}$ patients resemble those of patients with autoimmune liver disease but are different from those in hepatitis B patients. J Viral Hepat. 2019;26:422-31. https://doi.org/10.1111/jvh.12979.

4. Zignego AL, Ferri C, Pileri SA. Italian Association of the Study of Liver Commission on Extrahepatic Manifestations of HCV infection. Extrahepatic manifestations of hepatitis $\mathrm{C}$ virus infection: a general overview and guidelines for a clinical approach. Dig Liver Dis. 2007;39:2-17. https://doi.org/10.1016/j.dld.2006.06.008.

5. World Health Organization. WHO urges countries to invest in eliminating hepatitis. 2019. Available at: https://www.who.int/newsroom/detail/26-07-2019-who-urges-countries-to-invest-ineliminating-hepatitis. Accessed 26 July 2019.

6. Centers for Disease Control and Prevention. Surveillance for Viral Hepatitis - United States. 2016. Available at: https://www.cdc.gov/ hepatitis/statistics/2016surveillance/commentary.htm. Accessed 16 Apr 2018.

7. Eurostat. EU hepatitis death rate stable. Accessed at: http://ec.europa. eu/eurostat/web/products-eurostat-news/-/EDN-20180728-1?

8. Fedeli U, Grande E, Grippo F, Frova L. Mortality associated with hepatitis $\mathrm{C}$ and hepatitis $\mathrm{B}$ virus infection: a nationwide study on multiple causes of death data. World J Gastroenterol. 2017;23: 1866-71. https://doi.org/10.3748/wjg.v23.i10.1866.

9. World Health Organization. Global health sector strategy on viral hepatitis 2016-2021. 2016. Available at: http://apps.who.int/iris/ bitstream/10665/246177/1/WHO-HIV-2016.06-eng.pdf. Accessed June 2016.

10. Polaris Observatory. The authoritative resource for epidemiological data, modeling tools, training, and decision analytics to support global elimination of hepatitis B and C by 2030. Available at: http://www.hepbunited.org/assets/Webinar-Slides/8b54a78215/ POLARIS-Brief-181217.pdf.

11. Moon AM, Webb GJ, Aloman C, et al. High mortality rates for SARS-CoV-2 infection in patients with pre-existing chronic liver disease and cirrhosis: preliminary results from an international registry [published online ahead of print, 2020 May 21]. J Hepatol. 2020;S0168-8278(20):30305-6. https://doi.org/10.1016/j.jhep. 2020.05.013.

12. Allenza contro l'Epatite. Documento di posizione SCREENING CONGIUNTO HCV/COVID-19. 2020. Available at: https:// www.epatitec.info/cm-files/2020/06/22/position-paper-acescreening-congiunto-hcv-covid-19.pdf. Accessed 22 June 2020.

13. European Association for the Study of the Liver. EASL recommendations on treatment of hepatitis C 2018. J Hepatol. 2018;69:461511. https://doi.org/10.1016/j.jhep.2018.03.026. 
14. Alleanza Contro l'Epatite. ALLEANZA CONTRO L'EPATITE 2019 POSITION PAPER. 2019. Available at: https://www.epac. it/cm-files/2019/10/03/position-paper-hcv-def.pdf. Accessed 3 Oct 2019.

15. Gower E, Estes C, Blach S, Razavi-Shearer K, Razavi H. Global epidemiology and genotype distribution of the hepatitis $\mathrm{C}$ virus infection. J Hepatol. 2014;61:S45-57. https://doi.org/10.1016/j. jhep.2014.07.027.

16. Saraswat V, Norris S, de Knegt RJ, Sanchez Avila JF, Sonderup M, Zuckerman E, et al. Historical epidemiology of hepatitis $\mathrm{C}$ virus (HCV) in select countries - volume 2. J Viral Hepat. 2015;1:6-25. https://doi.org/10.1111/jvh.12350.

17. Maaroufi A, Vince A, Himatt SM, Mohamed R, Fung J, OpareSem $\mathrm{O}$, et al. Historical epidemiology of hepatitis $\mathrm{C}$ virus in select countries-volume 4. J Viral Hepat. 2017;24:8-24. https://doi.org/ 10.1111/jvh.12762.

18. Dolan K, Wirtz AL, Moazen B, Ndeffo-Mbah M, Galvani A, Kinner SA, et al. Global burden of HIV, viral hepatitis, and tuberculosis in prisoners and detainees. Lancet. 2016;388:1089-102. https://doi.org/10.1016/S0140-6736(16)30466-4.

19. Tanaka H, Tsukuma H, Yamano H, Oshima A, Shibata H. Prospective study on the risk of hepatocellular carcinoma among hepatitis $\mathrm{C}$ virus-positive blood donors focusing on demographic factors, alanine aminotransferase level at donation and interaction with hepatitis B virus. Int J Cancer. 2004;112:1075-80. https://doi. org/10.1002/ijc.20507.

20. World Health Organization. Guidelines for the screening, care and treatment of persons with hepatitis C infection. 2014. Available at: http://www.who.int/hiv/pub/hepatitis/hepatitis-c-guidelines/en/. Accessed Apr 2014.

21. World Health Organization. Guidelines for the screening, care and treatment of persons with chronic hepatitis $\mathrm{C}$ infection. Updated version July 2018. Available at: https://www.who.int/hepatitis/ publications/hepatitis-c-guidelines-2018/en/. Accessed July 2018.

22. World Health Organization. Sixty-ninth world health assembly. Draft global health sector strategies. Viral hepatitis, 2016-2021. 2016. Available at: http://apps.who.int/gb/ebwha/pdf files/ WHA69/A69 32-en.pdf. Accessed June 2016.

23. Ramadori G, Meier V. Hepatitis $\mathrm{C}$ virus infection: 10 years after the discovery of the virus. Eur J Gastroenterol Hepatol. 2001;13:46571. https://doi.org/10.1097/00042737-200105000-00001.

24. World Health Organization. Global hepatitis report. 2017. Available at: http://www.who.int/news-room/fact-sheets/detail/ hepatitis-c. Accessed Apr 2017.

25. World Health Organization. Global Status Report on Blood Safety and Availability 2016. Available at: http://apps.who.int/iris/ bitstream/10665/254987/1/9789241565431-eng.pdf?ua=1.

26. Piccinini V, Facco G, Catalano L, Pupella S, Grazzini G. Transfusion transmitted infection in Italy: blood donors epidemiological surveillance. Report 2013. Istituto Superiore di Sanità. Rapporti ISTISAN 14/26. 2013.

27. Fabrizi F, Martin P, Mess P. Control of HCV, HBV and HIV infections in hemodialysis. Giornale Italiano di Nefrologia. G Ital Nefrol. 2013;30(4):gin/30.4.11.

28. Fissell RB, Bragg-Gresham JL, Woods JD, Jadoul M, Gillespie B, Hedderwick SA, et al. Patterns of hepatitis $\mathrm{C}$ prevalence and seroconversion in hemodialysis units from three continents: the DOPPS. Kidney Int. 2004;65:2335-42. https://doi.org/10.1111/j. 1523-1755.2004.00649.x.

29. Di Napoli A, Pezzotti P, Di Lallo D, Petrosillo N, Trivelloni C, Di Giulio S. Lazio Dialysis Registry. Epidemiology of hepatitis C virus among long-term dialysis patients: a 9-year study in an Italian region. Am J Kidney Dis. 2006;48:629-37. https://doi.org/ 10.1053/j.ajkd.2006.07.004.
30. Saab S, Rheem J, Sundaram V. Hepatitis C infection in the elderly. Dig Dis Sci. 2015;60:3170-80. https://doi.org/10.1007/s10620015-3717-6.

31. Joy JB, McCloskey RM, Nguyen T, Liang RH, Khudyakov Y, Olmstead A, et al. The spread of hepatitis $C$ virus genotype 1a in North America: a retrospective phylogenetic study. Lancet Infect Dis. 2016;16:698-702.

32. Manjelievskaia J, Brown D, Shriver CD, Zhu K. CDC screening recommendation for baby boomers and hepatitis $\mathrm{C}$ virus testing in the US military health system. Public Health Rep. 2017;132(5): 579-84. https://doi.org/10.1177/0033354917719446.

33. Shiffman ML. The next wave of hepatitis $C$ virus: the epidemic of intravenous drug use. Liv Int. 38:34-9. https://doi.org/10.1111/liv. 13647.

34. Vandelli C, Renzo F, Romanò L, Tisminetzky S, De Palma M, Stroffolini T, et al. Lack of evidence of sexual transmission of hepatitis $\mathrm{C}$ among monogamous couples: results of a 10 -year prospective follow-up study. Am J Gastroenterol. 2004;99:855-9. https://doi.org/10.1111/j.1572-0241.2004.04150.x.

35. Tahan V, Karaca C, Yildirim B, Bozbas A, Ozaras R, Demir K, et al. Sexual transmission of HCV between spouses. Am J Gastroenterol. 2005;100:821-4. https://doi.org/10.1111/j.15720241.2005.40879.x.

36. Terrault NA. Sexual activity as risk factor for hepatitis C. Hepatology. 2002;36:S99-105. https://doi.org/10.1053/jhep.2002. 36797.

37. Terrault NA, Dodge JL, Murphy EL, Tavis JE, Kiss A, Levin TR, et al. Sexual transmission of hepatitis $\mathrm{C}$ virus among monogamous heterosexual couples: the HCV partners study. Hepatology. 2013;57:881-9. https://doi.org/10.1002/hep.26164.

38. Karageorgopoulos DE, Allen J, Bhagani S. Hepatitis C in human immunodeficiency virus co-infected individuals: is this still a "special population"? World J Hepatol. 2015;7:1936-52. https://doi. org/10.4254/wjh.v7.i15.1936.

39. Giraudon I, Ruf M, Maguire H, Charlett A, Ncube F, Turner J, et al. Increase in diagnosed newly acquired hepatitis $\mathrm{C}$ in HIV-positive men who have sex with men across London and Brighton, 20022006: is this an outbreak? Sex Transm Infect. 2008;84:111-5. https://doi.org/10.1136/sti.2007.027334.

40. Wandeler G, Gsponer T, Bregenzer A, Günthard HF, Clerc O, Calmy A, et al. Hepatitis C virus infections in the Swiss HIV Cohort Study: a rapidly evolving epidemic. Clin Infect Dis. 2012;55:1408-16. https://doi.org/10.1093/cid/cis694.

41. van de Laar T, Pybus O, Bruisten S, Brown D, Nelson M, Bhagani $\mathrm{S}$, et al. Evidence of a large, international network of HCV transmission in HIV-positive men who have sex with men. Gastroenterology. 2009;136:1609-17.

42. Puglia M, Stasi C, Da Frè M, Voller F. Prevalence and characteristics of HIV/HBV and HIV/HCV coinfections in Tuscany. Braz $\mathrm{J}$ Infect Dis. 2016;20:330-4. https://doi.org/10.1016/j.bjid.2015.11. 007.

43. Benova L, Mohamoud YA, Calvert C, Abu-Raddad LJ. Vertical transmission of hepatitis $\mathrm{C}$ virus: systematic review and meta-analysis. Clin Infect Dis. 2014;59:765-73. https://doi.org/10.1093/cid/ ciu447.

44. Indolfi G, Nesi A, Resti M. Intrafamilial transmission of hepatitis C virus. J Med Virol. 2013;85:608-14. https://doi.org/10.1002/jmv. 23522.

45. Henderson DK. Managing occupational risks for hepatitis C transmission in the health care setting. Clin Microbiol Rev. 2003;16: 546-68. https://doi.org/10.1128/cmr.16.3.546-568.2003.

46. World Health Organization. Hepatitis $\mathrm{C}$ in the WHO European region. Fact sheet - July 2018. Available at: http://www.euro. who.int/ data/assets/pdf file/0009/377253/fact-sheet-hepatitis-ceng.pdf?ua $=1$. Accessed July 2018. 
47. Centers for Disease Control and Prevention. Vital Signs: Evaluation of Hepatitis C Virus Infection Testing and Reporting — Eight U.S. Sites, 2005-2011. Available at: https://www.cdc.gov/mmwr/ preview/mmwrhtml/mm6218a4.htm. Accessed 10 May 2013.

48. American Association for the Study of Liver Diseases, Infectious Diseases Society of America. HCV Guidance: Recommendations for Testing, Managing, and Treating Hepatitis C. HCV Testing and Linkage to Care. 2017. Available at: http://www.hcvguidelines.org/ full-report/hcv-testing-and-linkage-care. Accessed 25 June 2019.

49. Crespo J, Cuadrado A, Perelló C, Cabezas J, Llerena S, Llorca J, et al. Epidemiology of hepatitis $\mathrm{C}$ virus infection in a country with universal access to direct-acting antiviral agents: data for designing a cost-effective elimination policy in Spain. J Viral Hepat. 2020;27: 360-70. https://doi.org/10.1111/jvh.13238.
50. U.S. Preventive Services Task Force. Draft recommendation statement and draft evidence review: screening for hepatitis $\mathrm{C}$ virus infection. Available at: https://www. uspreventiveservicestaskforce.org/Page/Document/draft-evidencereview/hepatitis-c-screening1. Accessed 27 Aug 2019.

51. Peeling RW, Boeras DI, Marinucci F, Easterbrook P. The future of viral hepatitis testing: innovations in testing technologies and approaches. BMC Infect Dis. 2017;17(Suppl 1):699. Published 2017 Nov 1. https://doi.org/10.1186/s12879-017-2775-0.

Publisher's Note Springer Nature remains neutral with regard to jurisdictional claims in published maps and institutional affiliations. 